УДК 1(091)

DOI dx.doi.org/10.24866/1997-2857/2020-3/156-164

\title{
B.B. Савчук*
}

\section{А.В. ДЕМИЧЕВ - ОСНОВАТЕЛЬ ПЕТЕРБУРГСКОЙ ТАНАТОЛОГИИ *}

\begin{abstract}
Петербургская танатология - важная страница философских движений второй половины XX в. Ее значение далеко выходит за временны́е и географические границы ее существования. В статье раскрываются истоки, питавшие мысль основателя Ассоциации танатологов Санкт-Петербурга А.В. Демичева, эволюция его взглядов, основной корпус идей, близкие по духу группы и сообщества - «Новая архаика» и некрореализм. Автор реконструирует советский идеологический контекст, в сопротивлении которому формировалось концептуальное содержание танатологии. Отмечен важный раздел танатологии - осмысление феномена русского кладбища, ставшего образом жизни соотечественника. Кроме содержательной характеристики идей, в статье уделено внимание формированию особого некропоэтического языка, на котором, согласно Демичеву, уместен разговор о смерти.
\end{abstract}

Ключевые слова: танатология, А.В. Демичев, «Новая архаика», некрореализм, некропоэтика, кладбище, смерть

Andrey Demichev, the founder of Saint Petersburg's thanatology. VALERIY V. SAVCHUK (Saint Petersburg State University)

Saint Petersburg's thanatology constitutes an important chapter in the history of late $\mathrm{XX}^{\text {th }}$ century philosophical movements. Its significance goes far beyond the temporal and geographical boundaries of its existence. The article reveals the sources that fed the thought of Andrey Demichev, the founder of the Association of Thanatologists of St. Petersburg, traces the evolution of his views and his connection with such groups and communities as «New archaic» and necrorealism. The author reconstructs the Soviet ideological context, against which the conceptual content of thanatology was formed. Particular emphasis is made on the formation of a special necropoetic language, which, according to Demichev, is appropriate for a conversation about death.

Keywords: thanatology, A.V. Demichev, «New archaic», necrorealism, necropoetics, cemetery, death

* САВЧУК Валерий Владимирович, доктор философских наук, профессор кафедры культурологии, философии культуры и эстетики, директор Центра медиафилософии Института философии Санкт-Петербургского государственного университета.

E-mail: savcuk.valeri@gmail.com

(C) Савчук В.В., 2020

** Работа выполнена при финансовой поддержке гранта РФФИ. Проект № 20-011-00144. 


\section{Введение}

Значение трудов Андрея Витальевича Демичева $^{1}$ - не в первенстве постановки философского вопроса о смерти: до него в истории как зарубежной, так и отечественной мысли существовала давняя традиция осмысления смерти (да и сам он о вкладе предшественников в танатологию проникновенно писал на страницах своих книг). И даже не в том, что он создал больше работ о ней, чем другие, организовывал резонансные симпозиумы и конференции, открыл альманах «Фигуры Танатоса» и применил танатологический метод к анализу близкого по духу важного художественного направления Петербурга - некрореализма. Значение трудов А.В. Демичева в том, что он пробуждал интерес к проблематике смерти в период ощутимых предсмертных судорог господствующей идеологической системы и дошел на этом пути до предела, до той границы, где его собственная жизнь столкнулась со смертью близкого человека, где он, словно бы прикоснувшись к смерти, искал язык, описывающий его опыт: «Писать - открывать скважину смерти. Быть выставленными ей. Чуять Ничто. Не владеть, а исполняться» [7, с. 48]. Его работы инициировали исследования многих современных танатологов, а он стал непременным собеседником идущих вслед за ним: «А.В. Демичев внес значительный вклад в становление и развитие российской философско-культурной танатологии» [12, с. 57]. Т.В. Мордовцева отмечала, что в трудах Демичева «проблема смерти открывает новое антропологическое ви́дение, позволяющее человеку обрести свою аутентичность перед страхом конца жизни» [11, с. 84], а филолог М.А. Дударева подчеркивает, что Демичев в «фундаментальной работе “Дискурсы смерти. Введение в философскую танатологию” обо-

1 Демичев Андрей Витальевич (08.11.1957 24.10.2000) - теоретик некрореализма и основоположник философской танатологии в России, организатор Ассоциации танатологов Санкт-Петербурга, философ, поэт и писатель. Окончил вечернее отделение философского факультета ЛГУ в 1981 г., здесь же успешно защитил в 1988 г. кандидатскую, а в 1997 г. - докторскую диссертацию («Философские и культурологические основания современной танатологии»). Доцент философского факультета Ленинградского/Санкт-Петербургского университета с 1990 г. С 1997 г. - ведущий научный сотрудник Санкт-Петербургского филиала Института человека РАН, директор Санкт-Петербургского филиала Московского института бизнеса и политики. значил и развил культурологические и философские основания современной танатологии» $[10$, c. 6]. И действительно, в его трудах были прояснены философские, антропологические и культурологические основания современной танатологии, пережившие свою эпоху и по-новому зазвучавшие в XXI в. Впрочем, историография и рецепция идей Демичева в российской танатологии еще ждут вдумчивого исследователя. Предваряя итоги, можно с определенностью сказать, что современные отечественные авторы, пишущие о смерти, но не упоминающие трудов Андрея Демичева, существенно занижают научную состоятельность своих работ.

\section{Новая архаика}

Интерес Демичева к теме смерти питали два истока. Первый был обозначен в кандидатской диссертации о категории «гармония»: она трактовалась как вид противоречия, разрешение коего с необходимостью приводило к теме гармонии человека и природы ${ }^{2}$. Уже на этом этапе закладывался фундамент подхода к феномену смерти как виду внутреннего противоречия, удержать которое автор пытался на пути поиска гармоничного отношения к смерти: начальный вариант его докторской диссертации назывался «Гармония смерти».

Вступление в 1990 г. в Общество философии и искусства «Новая архаика» (сооснователями были художник Вадим Драпкин, философ Валерий Савчук и режиссер и актер «До-Театра» Евгений Козлов), знакомство с концептами новой архаики, а затем и деятельное участие в их разработке стали вторым истоком. Демичева привлекла сложившаяся на заседаниях общества атмосфера, которую отличали искренность и серьезность, шедшие вразрез с набиравшей силу тотальной игрой и иронией, - все это оставило глубокий след в его творчестве. Впрочем, на это недвусмысленно указывал и сам автор: «Современная питерская философская танатология, хотя и густо замешана постмодерном, активирована была к жизни "Новой архаикой". Ee организационным отпочкованием можно считать Ассоциацию танатологов Санкт-Петербурга, в которую вошли, помимо меня... Валерий Савчук, Татьяна Артемьева и Михаил Уваров...» [3, с. 251]. Эту же мысль он повторяет в другом месте: «“Сигналы новоархаического искательства уже давно прорываются в эфире

2 Это стало лейтмотивом совместной с В.А. Белоусовым книги [1]. 
современного культуротворчества. "Новая архаика" - собирательно-артикулирующая интонация, установление голоса, первая весть, первый рассказ о вертикальной, многослойной, воздержанно-мужественной культуре, черпающей спокойную уверенность из материнского лона природы". Это один из последних пассажей моей статьи "Death on the run, или Игра со смертью", написанной почти десять лет назад и опубликованной в легендарном сборнике “Символы в культуре"...» [3, с. 250-251]. В предисловии к «Фигурам Танатоса» он конкретизировал начало своих танатологических штудий: «Решающим импульсом для его подготовки, а следовательно, и всей серии альманаха, стала лекция-беседа "Тема смерти в новой архаике", проведенная 11 декабря 1990 г. в знаменитой "Бродячей собаке", на фестивале Общества философии и искусства "Новая архаика". Что ж, все это... думаю, не случайно» [5, с. 4]. Вначале Ассоциация танатологов Санкт-Петербурга была общественной организацией, но после того, как в ее ряды органично влился Вадим Львович Рабинович, во многом усилиями которого в 1994 г. было организовано Санкт-Петербургское отделение Института человека РАН, директором которого он стал (ученый секретарь - Татьяна Владимировна Артемьева; после реформирования Института человека и слияния его с Институтом философии РАН петербургское отделение было переименовано в Санкт-Петербургское отделение Института философии РАН и просуществовало до 2004 г.), петербургская танатология получила академический статус.

В 1990-е гг,, в современном общественном сознании прочно ассоциирующиеся с определением «лихие», в кино господствовали доведенный до крайности нуар, треш, хардкор, сплэттер, зомби-хоррор: жизнь людей представлялась обреченной и беспросветной, избыточно жестокой, а насилие выступало нормой; в архитектуре царили китч, капиталистический романтизм с неизменными башенками и высокими и плотными заборами; в изобразительном искусстве - некрореализм. Для философов и художников этот период, отмеченный интеллектуальной и художественной свободой, породил веер самых различных, порой противоречивых направлений, течений, концептов. В философии был расцвет постмодернизма; новая архаика и «Новые тупые». Интенция новой архаики к отказу от тотальной игры и иронии совпала с устремлениями танатолога, поскольку его иро- ния не сводится к насмешке, но привносит элемент провокации в устоявшееся отношение к смерти: «Ирония легко становится судьбой» [7, c. 22]. Свобода же понималась им как растворение в коллективном теле, подобное радости ритуального жертвоприношения, растворение в космическом мироустройстве, благодаря чему реализуется подспудное желание равенства на фоне кичливого торжества финансово-чиновничьей верхушки.

Говоря о становлении танатологии, трудно обойти вниманием интеллектуально-художественный контекст 1990-х гг. Осознав свободу, все заговорили в голос, многое было доведено до крайности; даже, казалось бы, скомпрометировавшая себя марксистко-ленинская идеология, понятая в духе оптимизма и веры в светлое будущее, не сдавала позиций: «Не может и не должно быть сомнения, что только оптимистическая уверенность в возможности достижения практического бессмертия человека должна быть присуща марксистско-ленинской философии, что лишь такая позиция достойна ее революционного, преобразующего мир и самого человека предназначения $<\ldots>$ в наши дни речь должна идти уже о том, чтобы отвратить от людей не только преждевременную, но и всякую смерть. Это значит, что пора во весь голос говорить о практическом бессмертии как главной цели общественного прогресса...» [2, c. 226-227]. Налицо отказ от традиции естественной трактовки физической смерти как непреложности последнего предела. Чутко реагируя на ожидание философских идей (сегодня сказали бы: концептов) интеллектуальным сообществом, вернее говоря - на недоверие к скомпрометировавшей себя философии в отечественном пространстве, Демичев по-пастернаковски предпочитал поэзию, прозу, эссеистику, реализацию художественных проектов, в них он искал язык, который адекватно отражал бы его понимание смерти в культуре.

В эпоху перестройки идеологическая хватка окончательно ослабла и искусству уже не предписывались ни интонация безоговорочного оптимизма, ни преображение мира из неразумного в разумное состояние, из безобразного в «прекрасное». Когда же само искусство провозгласило свою смерть, тогда был заявлен плюрализм ориентиров, среди которых выделялись и архаический космос, и торжество низменной стороны человека, и разоблачение тоталитарной сущности деклараций о равенстве, и реа- 
лизм «живого трупа» - не в изначальном смысле ожившего мертвеца, но трупа разлагающегося. Однако же их запредельный оптимизм был едкой карикатурой на жизнеутверждающий оптимизм: «После смерти наступает жизнь что надо, мужики!» - так пели герои фильма «Лесоруб» (1985) Евгения Юфита. Многообразие проявлений смерти ускользает от определенности, смерть отстаивала право быть фундаментальным различием, противящимся любой тоталитарной всеобщности. На постмодернистскую сцену выходили не по-федоровски воскресшие отцы, но ожившие трупы с их рефлекторными и спазматическими движениями зомби, у которых исключались свобода воли и любая партикулярная ритмика движений. В то же время герменевтика тонких критических намеков в адрес идеологической системы была отброшена за ненадобностью, как и сама аргументированная критика: ее сменили презрительное игнорирование, беспамятство и забвение предшествующего периода истории. Анализ истоков танатологии был бы однобок без учета системы референций к постструктуралистским концептам и методологическим установкам, бытовавшим в ту пору в философской и художественной среде Петербурга.

Интенсивному переводу, реферированию и жадному усвоению, а в итоге - письму в духе понятий и категорий штудируемого мыслителя танатология, вслед за новой архаикой, противопоставляла самобытную модель существования. Демичев отвергал отношение к смерти, бытовавшее в идеологических изводах советской эпохи с ее культом молодости, оптимизма, ориентацией в будущее, - то состояние, в котором смерть была не узнана, а ее присутствие не затрагивало ни личного плана, ни экзистенциальных переживаний, поскольку смерть оказывалась немыслимой, невообразимой, невозможной ${ }^{3}$. Демичев вслед за предшественниками, которых он нашел в том числе и среди «пассажиров “философского парохода"», чутко реагировал на разыгрывающуюся травестию жизни и смерти. Он сделал важный вывод: борьба со смертью в советской России, а затем и в СССР оборачивается борьбой с жизнью. Мертвецы, не зарегистрированные по своему ведомству, решительно наруша-

\footnotetext{
3 Писатель и литературовед второй волны эмиграции Л.Д. Ржевский сравнивает сознание советского человека с психикой ребенка, которому смерть еще не ведома и для которого поэтому невозможна $[13$, c. 45$]$.
}

ют границу, пружинисто занимают открытые линии, подвергают инспекции, утилизации, инвентаризации все живое, становясь на место живых, становясь «живее всех живых».

Советским избыточно оптимистичным декларациям Демичев противопоставил иную позицию: «Деструктивная стратегия табуирования, вытеснения смерти из внутрижизненного повседневного человеческого существования, как правило, происходит из страха идентификации с покойником и, следовательно, моделирует отношение человека прежде всего к собственной смерти или, в данном случае, скорее стремление избежать этих отношений, вычеркнуть возможность собственной смерти как перехода к несуществованию из проективности своего бытия. Конструктивная стратегия, напротив, принимает модель смерти как несуществования, но легче всего она разворачивается по отношению к смерти другого. В этом случае происходит весьма эффективная эмоционально-энергетическая подпитка смертью, близость которой возбуждает силы сопротивления и солидарности остающихся» [8, с. 47].

Отказ от официальной установки и творчество вне системы обеспечивали танатологии свободу в выборе как предмета, так и методов исследования, а экзистенциальная вовлеченность в тему смерти давала импульс исследовательскому азарту. Однако полная независимость и самодостаточность танатологии мнима, ибо следует учитывать, что регистры некропроизводства и их скрытые связи с героическим социалистическим строительством намного многообразнее и глубже, чем представляется на первый взгляд, даже если мы удерживаем в сознании, что «густой замес постмодернизма» инициировал танатологию, выросшую из новоархаического искательства и космоустроительных интенций. Критика настоящего положения дел, осуществляемая Демичевым, исходила из запротоколированной смерти культуры, последовавшей за смертью Бога, метафизики, человека; она не отбрасывала труп культуры, но сосредоточила все свое внимание на поиске «разлагающихся» фрагментов ее мертвых структур. Смерть может выглядеть иначе, если применить к ней практики анализа, характерные для современной западной мысли. Это давало шанс не только преодолеть интеллектуальный провинциализм, но и получить неожиданно весомые и востребованные по сей день результаты. Стремление Андрея Демичева вер- 
нуть в философию вопрошание о смерти казалось экстравагантным проектом, а то и вовсе нефилософским предприятием. Однако радикализм его подхода, неизбежно оказывающегося за рамками классической рациональности, заключается в том, что он отвечал на вопросы, не дающиеся ни описанию, ни строгой рефлексии. Здесь требовались методы, свободные от диктата детерминистской причинности: «...раскрыть статус философской танатологии как мировоззренческого и ориентирующего знания, в том числе в горизонте постмодернистского задания современной культуры» [8, с. 10].

Чью позицию выражает автор? Не философский антрополог, не теолог - тут говорит танатолог, отрицающий постулаты Просвещения, которое если и упоминало о смерти, то уклончиво, невнятно, вскользь. Хотя понимание смерти Демичевым и исходит из разрыва трансцендентального и эмпирического планов, его интересуют точка прикосновения смерти и последующий процесс перехода организма в неорганическое состояние. Опираясь на Фрейда, он делает важный вывод: «Организм должен умереть собственной смертью, своим путем вернуться в неорганическое, исчерпав все ресурсы уклонения. Организм заботится о себе... лишь в силу стремления избежать не своей смерти, а не смерти вообще. Смерть усложняет свое приближение, делает это приближение обходным и лабиринтным» [7, с. 44].

Итогом первого этапа танатологических исследований стал анализ смерти не столько как субъективного опыта и экзистенциального переживания, сколько как социокультурного и идеологического конструкта, подверженного историческим изменениям. Андрей Демичев задал возможность разговора о смерти, чего не случилось бы, не будь у него опыта «парада смертей» в ситуации постмодерна. И здесь парадокс, запеленгованный Демичевым: после объявления стольких смертей - от Бога до метафизики - сам феномен смерти не поддается схватыванию ни с помощью строгих дискурсивных практик, ни с помощью художественных средств. Искомую цель он определил как отчаянное «стремление гармонизации негармонизируемого» [7, с. 49].

\section{Некрореализм}

Следующей важной вехой танатологических исследований Демичева стал интерес к художественному течению - некрореализму, возникшему в 1980-х гг. в Ленинграде, в среде «Но- вых художников» ${ }^{4}$. Его отцом являлся Евгений Юфит, среди ранних сподвижников которого были Олег Котельников, Андрей Мертвый (Курмоярцев), Евгений Дебил (Кондратьев), Юрий Циркуль (Красев), Леонид Трупырь (Константинов). История и практика некрореализма сегодня исследованы основательно, ему посвящены диссертационные исследования, монографии, статьи, альбомы и каталоги важнейших выставок. Фильмография и перечень основных работ, выставляемых в самых престижных отечественных и зарубежных музеях, тоже внушительны ${ }^{5}$. Все это так, но Андрей Демичев принадлежал к числу первых философов, которые обратили внимание на феномен некрореализма ${ }^{6}$ в ленинградском контексте как на продукт эпохи, выразивший самоощущение художников позднесоветского периода: «Современный советский некрореализм - одна из форм осознания или, скорее, художественно-инстинктивного ощущения господства смерти в выпрямленном ландшафте небытия» [4, с. 132] - выпрямленном господствующим мироощущением, сформированным советской идеологической машиной.

Некрореализм был тесно связан с контекстом советского времени, вне и без которого его протестные настроения, мистификацию революционной мифологии (смерть освобождает человека от конкретной идентичности и тем самым помещает его в воображаемое коллективное тело созидателей будущей счастливой жизни, ради коей оно жертвует отдельным членом сообщества), доведение ее до героической абсурдности понять крайне сложно. Размышляя об этом, Андрей Демичев определяется с истоком своего интереса: «Чем, собственно, инте-

${ }^{4}$ В 1982 г. Тимур Новиков, Иван Сотников, Евгений Козлов и их друзья - Олег Котельников, Кирилл Хазанович - объединились в группу «Новые художники».

5 Кинематографический анализ некрореализма см. в: [15].

${ }^{6}$ Следует все же отметить, что некрореализм возник не еx nihilo. Согласно искусствоведу В.В. Пацюкову, искусство 1960-х гг. «открыло новый некрополь, город мертвых»: «Вадим Сидур создал искусство “гроб-арта”. Игорь Макаревич спеленал себя, как мумию. Кабаков вырос в шкафу. Владимир Янкилевский посадил всех своих персонажей в ящики, напоминающие гробы. Герловины (супруги Римма Герловина и Валерий Герловин. - прим. авт.) поместились в пространстве кубика. Иван Чуйков пробивался сквозь заколоченные окна в нарисованные мнимые пространства...» [9, с. 22]. 
ресен некрореализм? Что следует ценить в нем прежде всего? Для меня, танатолога, ценность некрореалистической продукции очевидна. И она заключается в актуализации и попытках визуализации смерти как прижизненного состояния. <..> Аффект смерти не только травматичен, но через травматичность и конструктивен, исполняет идентификационную функцию» [7, c. 183]. Таким образом, осмысление некрореализма шло не только из зоны, которую Демичев называл постбытием, то есть из зоны умаления смерти, ее негации и забвения, господствующих в эпоху развитого социализма, но и изнутри художественного процесса. В частности, он не просто пишет о кладбище, устраивает конференции, собирает очередной том «Фигур Танатоса», а и деятельно участвует в фотографических проектах Владимира Кустова ${ }^{7}$. Их интересовали эстетика непроходимых оградок, покосившихся крестов и памятников из подручного материала, атмосфера заброшенных могил и смена времен года, которая меняет контекст знаков вечности и рождает щемящее чувство забвения ${ }^{8}$. Кладбище, утверждает Демичев, для советского человека стало образом жизни - героической жизни отцов, превратившейся в абсолютный образец для последующих поколений. Но танатологический проект говорит нам: кладбища, как и люди, тоже умирают. Возникновение некрореализма, а затем и танатологии совпало со сломом общественного строя и переводом всех отношений, включая искусство и отношение к смерти, на рыночные рельсы.

Демичев ценил поэтическое слово, любил философию и жизнь. Поэтому его позицию отличал не только интерес к конкретным работам, фильмам и проектам некрореалистов, кои сопровождаются рефлексиями-обобщениями с позиций танатологии, где танатологическое тесно сплетается с некрореалистичным, а художественное становится концептуальным жестом. К таким сплавляющим до неразличимости художественный и танатологический подходы относится проект виртуального кладбища «Новые Литераторские мостки» (1994),

${ }^{7}$ См.: «Русское кладбище: опыт идентификации» (1994-1995) (авторы: А. Демичев, В. Кустов; галеpeя Laterna Magica, Хельсинки, Финляндия, декабрь 1998 г.), «Мавзолей как убежище формы» (авторы: А. Демичев, В. Кустов; Музей В.И. Ленина в Тампере, Финляндия, июнь 1999 г.) и др.

${ }^{8}$ Об этом проекте см. программную статью альманаха: [6]. для которого отечественные (петербургские) философы, поэты, писатели, художники написали автоэпитафии [14, с. 234-240]. Поскольку о смерти Демичев говорил без суеверия, он создал ироничную автоэпитафию:

\section{ЗАНИМАЛСЯ СМЕРТЬЮ ИГРАЛ С НЕЙ HO ВСЕ РАВНО УМЕР ПОКА 9}

\section{Некропоэтическая нехватка языка}

Некрореализм дал художественный ресурс танатологу и чувство свободы в поиске адекватного языка и нужной интонации в разговоpe о невозвратной утрате близкого человека: «Смерть близкого, “символическая смерть” разверзает внутреннее, сокровенное пространство, бытие-вне-себя, бездну и восторг именования» [7, с. 194]. Понятия научной философии, как она понималась в ту пору, и ее легитимных разделов - этики, эстетики, социальной философии и антропологии - не смогли удовлетворить его. «Хочешь быть искренним - забудь о жанрах», - таково кредо Андрея Демичева. И он ему следовал. И пусть «приставленные машинки» филолога или миколога (Ницше) дают ответы на чужие вопросы, его тексты отвечают на свои... «Запросы», - реактивно продолжит едкий комментатор. Но Демичев его проигнорирует. Распахнутая интонация текстов позднего периода выдержана без оглядки на цинизм и прищур снисходительности. И тем, как сегодня становится все яснее, Демичев преступает эпоху nост-; иными словами, в ситуации культурной избыточности оригинальность заключается в самой интонации, рождающей возможность разговора о событии смерти, который без автора не состоялся бы.

Задаваясь своими вопросами без прищура «могу и иначе», Андрей Демичев настойчиво возвращается в мастерскую, к месту одиноких ночных медитаций. Пишущий одинок? Всегда

9 Злой иронией, отметающей иронию постмодернистскую, ее игру и ускользание от однозначности, является неуклюжее участие словоруба - специалиста по нанесению надписей и художественных деталей на надгробный камень, который по своей инициативе расставил запятые, исправив текст автоэпитафии. Именно так выглядит сегодня надпись на могиле Андрея Витальевича Демичева на Смоленском кладбище Петербурга: «Занимался смертью, играл с ней, но все равно умер, пока». 
перед лицом ночи и смерти. Можно ли публично размышлять о смерти? Мог ли на рыночной площади говорить о смерти Сократ? И почему тот, кто размышляет о смерти, часто приходит к поэзии, к мастерству гравировки состояния, к торжеству точно схваченного мгновения, уместного слова и жеста? Демичевская доктрина танатологии, определяя завод смерти, делает очевидной инвалидность уже-давно-мертвого дискурса философии как науки, не способной вовлеченно размышлять о смерти.

В мастерской Платона - так назвал его сын место, где по ночам работал Андрей Демичев, он всматривается в лицо смерти, размышляет о ней и ей же открывается, вопреки предостережениям Спинозы: «Мудрый ни о чем не думает меньше, нежели о смерти, ибо мудрость есть мудрость жизни, а не смерти». А как иначе? Ведь предмет танатолога - смерть, о которой человеку не то что думать, дышать не хочется в ее присутствии. Ведь не пришел же на казнь учителя философ, «сказавшись больным». Задумавшийся о смерти остается один на один с вечностью, со всеми предшественниками и со всеми будущими поколениями. Смерть проверяет всех: «О том, как ты жил, можно сказать только после того, как ты умер». Всех, ну и?.. Другому бы хватило, Демичев же и нас, живущих, окликает, авось воскреснем для подлинной жизни.

Парафразы, аллюзии, риторические вопросы и перебои стиля... Его тексты - как лента Мёбиуса (вот банальность прилипчивая, недаром у Демичева - «клейкая»): начинает о смерти, а заканчивает жизнью; и, напротив, когда говорит о жизни - всплывают «маски жизни, играющие смерть». Провидческое движение руки как движение судьбы? «Философ живет в книге». Он собирает картину смерти постранично, по прозрениям и знакам ее понимания. Кто-то весь день живет, глядя на экран монитора, кто-то сторожит выгоду, а кто-то принужден быть при мысли, как приговский милицанер при свистке, о смерти. О ней его и спрашивают. А он? Книгой соединяет философское наукообразие и поэтическое вдохновение; последнее, впрочем, изгонялось из платоновской Академии. Но когда поэт берет верх, письмо Андрея Демичева вызывает во мне отклик. Он творит свой некропоэтический космос, как другие кладут русскую печь - чтобы было тепло спать и уютно жить. Для его описания он находит яркие поэтические образы: биолетье, медные трупы, некроволновая речь, смертоуборочные маши-
Hbl. Двигаясь по страницам книги (которые, как и листья его деревьев, «пробивают отверстия роста») без страховки - без полуоборота лица смерти, - раздражаешься, что все время не о том и что смерть таится, не проступает, хотя и тронута зеленью слов: «И юн. Июнь». Когда она есть - меня нет.

«Что ж, нужно сегодня свихнуться», - то ли утверждает, то ли спрашивает Андрей Демичев, оглядывая постмортальный пейзаж за окном или картину некрореалиста Владимира Кустова в своем директорском кабинете. Директор филиала Института бизнеса и политики - танатолог. Казалось бы, несуразность. Но нет. Это всего лишь русская специфика танатологии. И в этом нас тоже убеждает Андрей Демичев.

Однако может ли мысль, увлеченная поэтическим периодом, родить истину смерти? Ведь его, танатолога, порождающий мир рефлексивен: блестящий шахматный игрок, двигающий слова как фигуры, но пойманный желанием смысла, он входит в мастерскую Платона вопреки геометрии мысли. А за подмогой танатолог обращается не только к иностранным авторам М. Бланшо, Ф. Кафке, М. Фуко, Ж. Деррида, Ж. Бодрийяру, но и к предшественнику танатологии Ивану Тимофеевичу Фролову, проводнику эстезиса Алексею Алексеевичу Грякалову, к Мерабу Мамардашвили, любителю устной речи, к оппоненту его диссертации Валерию Подороге, к Аркадию Драгомощенко - мастеру паратаксиса, к спящему сыну Платону.

Борхес, предчувствуя смерть, написал книгу. Все думали, что речь будет о смерти, а он по крупицам собрал минуты счастья. Чтобы писать о смерти без иронии, нужно быть Николаем Федоровым или Морисом Бланшо. Иначе - диссертационное занудство и легковесность. Ведь дабы заклясть смерть, наша культура изобрела письмо, которое связано «с жертвоприношением самой жизни» (М. Фуко). Но когда письмо захватывает территорию Танатоса, тогда появляется возможность танатологии. К ней мы идем от известного, от истории вопросов, поставленных другими, от изложения взглядов, касаясь существа дела предшественников и переживая моменты понимания. В такие моменты рождаются собственные выводы Демичева, например: «Для русского человека смерть - поражение; жизнь - игра с выбыванием»; а художник или теоретик некрореалистического направления сознательно стремится «занять позицию выбывания и, следовательно, скомпрометировать не 
только эту идеологию, но и идеологию как таковую» [8, с. 21]. В теоретическую постановку вопроса о смерти, в книгу вплетается личная трагедия, переживаемая автором, тема смерти усложняется, и, наконец, читатель оказывается экзистенциально вовлеченным в переживание смерти близкого человека. Здесь совпадают символ, поэтический образ и мысль. Такова логика жизни, она же логика танатологии.

На позднем этапе недолгого, но яркого творческого пути Андрей Демичев осмыслял опыт переживания смерти близкого человека; то был этап поиска адекватного языка для описания этого опыта, этап поэзии, прозы и некропоэтики. Отбрасывая сомнения и избегая оговорок, Демичев, используя все свои дарования и прилагая все силы, нашел философско-поэтический язык, который точно схватывал и описывал существо опыта, именуемого «смерть». Его мысль задевает существо дела смерти, а поэзия «вечной эротической тягой в жизненочи вращает колесо жизни»; вместе они - мысль и не разъятая с ней поэзия - суть его танатологии.

\section{СПИСОК ЛИТЕРАТУРЫ}

1. Белоусов В.А., Демичев А.В. Гармония: противоречие, связь. Владивосток: Изд-во Дальневост. ун-та, 1991.

2. Вишев И.В. Проблема личного бессмертия. Новосибирск: Наука, 1990.

3. Демичев А.В. «Новая архаика» и современная питерская танатология // Философский век. Вып. 21: Науки о человеке в современном мире. Ч. 1. СПб.: Санкт-Петербургский Центр истории идей, 2002. С. 250-253.

4. Демичев A.B. Death on the run, или Игра со смертью // Символы в культуре: сборник статей / Отв. ред. В.В. Савчук. СПб.: Изд-во СПбГУ, 1992. С. 129-142.

5. Демичев А.В. Предисловие // Фигуры Танатоса. Вып. 1: Символы смерти в культуре. СПб.: Изд-во СПбГУ, 1991. С. 3-5.

6. Демичев А.В. Русское кладбище: опыт идентификации // Фигуры Танатоса. Вып. 6: Кладбище. СПб., 2001. С. 87-97.

7. Демичев А.В. Территория Танатоса. СПб.: Академия исследования культуры, 2020. (в печати)

8. Демичев А.В. Философские и культурологические основания современной танатологии: дисс. ... д-ра филос. н. СПб., 1997.

9. Другое искусство? // Декоративное искусство СССР. 1991. № 7. С. 19-25.
10. Дударева М.А. Поиски «иного царства» в русской литературе XIX - начала XX века: фольклорная эстетика. М.; СПб.: Нестор-История, 2018.

11. Мордовцева Т.В. Идея смерти в культурфилософской ретроспективе. Таганрог: Изд-во ТИУиЭ, 2001.

12. Павленко А.А. Танатологическая концепция культуры России в работах А.В. Демичева // Ученые записки Комсомольского-на-Амуре государственного технического университета. 2013. Т. 2. № 4. С. 57-60.

13. Ржевский Л. Язык и тоталитаризм. Мюнхен: Ин-т по изучению истории и культуры CCCP, 1951.

14. Савчук В.В. Конверсия искусства. СПб.: Петрополис, 2001.

15. Умер некрореализм // Ежеквартальный журнал «Сеанс». 15.12.2016 [Электронный ресурс]. - Режим доступа: https://seance.ru/articles/ goodbye-yufit

\section{REFERENCES}

1. Belousov, V.A. and Demichev, A.V., 1991. Garmoniya: protivorechie, svyaz' [Harmony: contradiction, connection]. Vladivostok: Izd-vo Dal'nevost. un-ta. (in Russ.)

2. Vishev, I.V., 1990. Problema lichnogo bessmertiya [The issue of personal immortality]. Novosibirsk: Nauka. (in Russ.)

3. Demichev, A.V., 2002. «Novaya arkhaika» i sovremennaya piterskaya tanatologiya [«New archaic» and modern Saint Petersburg's thanatology]. In: Filosofskii vek. Vyp. 21: Nauki o cheloveke v sovremennom mire. Ch. 1. SanktPeterburg: Sankt-Peterburgskii Tsentr istorii idei, 2002, pp. 250-253. (in Russ.)

4. Demichev, A.V., 1992. Death on the run, ili Igra so smert'yu [Death on the run, or the game with death]. In: Savchuk, V.V. ed., 1992. Simvoly v kul'ture: sbornik statei. Sankt-Peterburg: Izd-vo SPbGU, pp. 129-142. (in Russ.)

5. Demichev, A.V., 1991. Predislovie [Introduction]. In: Figury Tanatosa. Vyp. 1: Simvoly smerti v kul'ture. Sankt-Peterburg: Izdvo SPbGU, 1991, pp. 3-5. (in Russ.)

6. Demichev, A.V., 2001. Russkoe kladbishche: opyt identifikatsii [Russian cemetery: an attempt of identification]. In: Figury Tanatosa. Vyp. 6: Kladbishche. Sankt-Peterburg, 2001, pp. 87-97. (in Russ.)

7. Demichev, A.V., 2020. Territoriya Tanatosa [The territory of Thanatos]. Sankt-Peterburg: 
Akademiya issledovaniya kul'tury, 2020. (in print) (in Russ.)

8. Demichev, A.V., 1997. Filosofskie i kul'turologicheskie osnovaniya sovremennoi tanatologii [Philosophical and cultural studies foundations of modern thanatology], dissertatsiya doktora filosofskikh nauk. Sankt-Peterburg. (in Russ.)

9. Drugoe iskusstvo? [Other kind of art?], Dekorativnoe iskusstvo SSSR, 1991, no. 7, pp. 1925. (in Russ.)

10. Dudareva, M.A., 2018. Poiski «inogo tsarstva» v russkoi literature XIX - nachala XX veka: fol'klornaya estetika [The quest for «another world» in Russian literature of the XIXth - early XXth century: folklore aesthetics]. Moskva; SanktPeterburg: Nestor-Istoriya. (in Russ.)

11. Mordovtseva, T.V., 2001. Ideya smerti v kul'turfilosofskoi retrospective [The idea of death in the retrospect of philosophy of culture]. Taganrog: Izd-vo TIUiE. (in Russ.)

12. Pavlenko, A.A., 2013. Tanatologicheskaya kontseptsiya kul'tury Rossii $\mathrm{V}$ rabotakh A.V. Demicheva [Thanatological concept of Russian culture in the works of A.V. Demichev], Uchenye zapiski Komsomol'skogo-na-Amure gosudarstvennogo tekhnicheskogo universiteta, Vol. 2, no. 4, pp. 57-60. (in Russ.)

13. Rzhevskii, L., 1951. Yazyk i totalitarizm [Language and totalitarianism]. Munich: In-t po izucheniyu istorii i kul'tury SSSR. (in Russ.)

14. Savchuk, V.V., 2001. Konversiya iskusstva [Conversion of art]. Sankt-Peterburg: Petropolis. (in Russ.)

15. Umer nekrorealizm [The death of nekroralism]. URL: https://seance.ru/articles/ goodbye-yufit (in Russ.)

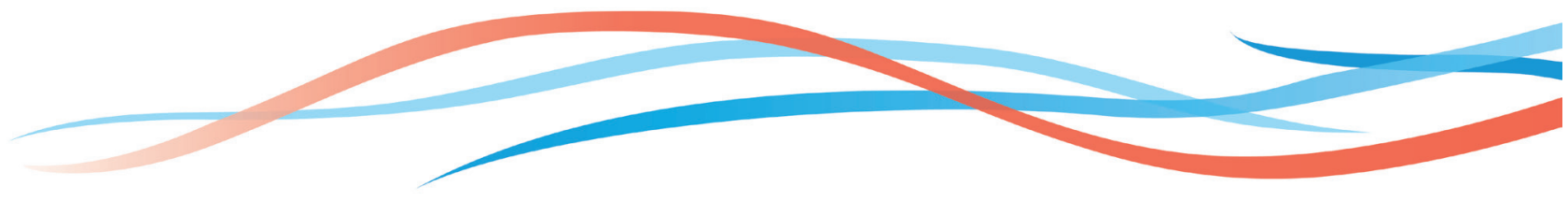

